\title{
Sensitivity of some human pathogenic yeasts and systemic fungi to myxin
}

\author{
AWATAR S. SEKHON AND ERIKA HARGESHEIMER \\ From the Provincial Laboratory of Public Health, University of Alberta, Edmonton, Alberta, Canada T6G 2J2
}

SYNOPSIS Myxin, a relatively new antibacterial and antifungal antibiotic, produced by a species of Sorangium, was used to investigate its effectiveness against some yeasts and dimorphic fungi associated with human diseases. Results indicated that the minimal fungicidal concentrations (MFC) of myxin for Candida albicans, C. krusei, C. parapsilosis, C. tropicalis, and Torulopsis glabrata were $0 \cdot 39-6 \cdot 25 \mu \mathrm{g} / \mathrm{ml}$, and for $C$. guilliermondii and $C$. tropicalis $12 \cdot 5-25 \mu \mathrm{g} / \mathrm{ml}$. The MFC for Blastomyces dermatitidis and Sporothrix schenckii was 0.195 and $6.25 \mu \mathrm{g} / \mathrm{ml}$, respectively. The MFC for these two systemic fungi for amphotericin B (fungizone) was $0 \cdot 39-0.78$ and $6 \cdot 25 \mu \mathrm{g} / \mathrm{ml}$. It seems that myxin is more effective against $B$. dermatitidis than amphotericin $B$. The isolate of Coccidioides immitis was found to be very sensitive to myxin (MFC, $0.78-1.56 \mu \mathrm{g} / \mathrm{ml}$ ).

Myxin, a relatively new antibiotic, produced by a species of Sorangium (Peterson, Gillespie, and Cook, 1966), has been reported to inhibit the growth of Gram-negative and Gram-positive bacteria, several plant pathogenic and saprophytic fungi, yeasts, and actinomyces (Peterson et al, 1966). Recently, it has been observed that strains of Sorangium (= Lysobacter antibioticus, Christensen, 1973) inhibited the growth of a strain of Scopulariopsis brevicaulis, which was the aetiological agent of deep scopulariopsosis (Sekhon, Willans, and Harvey, 1974). Despite the broad known spectrum of activity of myxin, its effectiveness has not been determined against most fungi which cause disease in man. In order to fill this gap, the present study was conducted to determine the activity of myxin against dimorphic fungi which cause blastomycosis, coccidioidomycosis and sporotrichosis, as well as some human pathogenic yeasts. Comparative studies were also conducted with amphotericin $B$, the most commonly used antibiotic in cases of systemic fungal infections.

\section{Material and Methods}

ORGANISMS

Details relating to their sources are given in table $\mathrm{I}$.

CULTURAL CONDITIONS

The species of yeasts and the dimorphic fungi were

Received for publication 16 December 1974. maintained on Phytone-yeast extract agar (BBL) and brain heart infusion agar (BHI, Difco), respectively, at $37^{\circ} \mathrm{C}$.

\section{INOCULUM PREPARATION}

Inoculum for the yeasts, Blastomyces dermatitidis and Sporothrix schenkii, was prepared by suspending a loopful of growth (48-168 hours old) in $20 \mathrm{ml}$ of sterile distilled water in a screw-capped bottle. This suspension was shaken vigorously. Spectrophotometric readings taken at $520 \mathrm{~nm}$ ranged from 80 to $90 \%$ transmission. For Coccidioides immitis, $5 \mathrm{ml}$ of sterile distilled water was pipetted into the screwcapped culture slant under the inoculation hood and, after shaking, the suspension was transferred into a sterile bottle that already had $15 \mathrm{ml}$ of sterile distilled water. The transmission reading of this suspension was $95 \%$ at $520 \mathrm{~nm}$.

\section{SUSCEPTIBILITY TEST}

Susceptibility studies were carried out using yeast nitrogen broth (Difco; Yeast nitrogen base, $6.7 \mathrm{~g}$; 1-asparagine, $1.5 \mathrm{~g}$; dextrose, $10 \mathrm{~g}$; deionized distilled water, 1 litre; sterilized through membrane filter). The procedure used for the test was essentially the same as described in the Center for Disease Control's manual (Haley, 1972). Tube number 1 contained 6 $\mathrm{ml}$ of broth and all the other tubes contained $5 \mathrm{ml}$. The myxin used in this study was obtained from Hoffman-LaRoche Inc, Nutley, New Jersey (RO $7-4488$, Lot SM-4, contained $20 \%$ water). The amphotericin B (fungizone) was the product of E. R. 


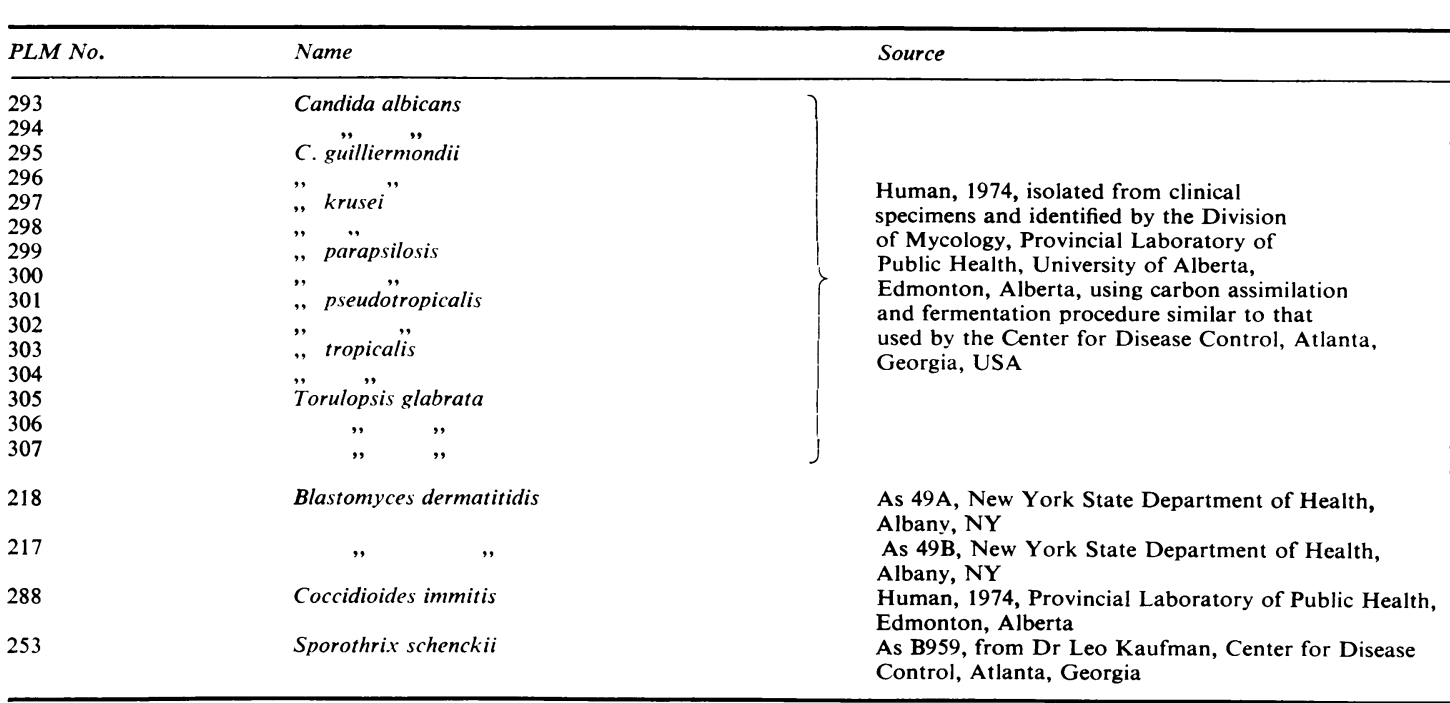

Table I Sources of the human pathogenic yeasts and systemic fungi

Squibb \& Sons Ltd, Montreal. Stock solutions of myxin and amphotericin B were made in acetone and dimethylformamide, respectively $(1 \mathrm{mg} / \mathrm{ml})$, and added to the first tube $(4 \mathrm{ml})$ to yield a final volume of $10 \mathrm{ml}$ in this tube. From this tube, after mixing the solution well, an aliquot of $5 \mathrm{ml}$ was withdrawn to prepare further serial dilutions (200-0.195 $\mu \mathrm{g} / \mathrm{ml}$ of the broth). With the exception of medium and antibiotic controls $(0 \cdot 195 \mu \mathrm{g} / \mathrm{ml})$, each tube including solvent controls was inoculated by pipetting $0.05 \mathrm{ml}$ of the previously prepared inoculum suspension. These tubes were then incubated at $30^{\circ} \mathrm{C}$ until growth was apparent in some of the tubes (48-72 hours for the yeasts, and 96-120 hours for the dimorphic fungi). At the end of the incubation period the tubes were shaken and examined for growth. The first tube showing visible growth, and the next two higher concentrations were used to inoculate Sabouraud dextrose agar (SDA) plates for yeast strains and the BHI slants for dimorphic fungi. In every case transfers from the tube showing visible growth were found to be viable. The lowest concentration from which no growth was obtained was recorded as the minimal fungicidal concentration (MFC).

It was discovered that growth was inhibited in the first two tubes of solvent controls, that is, the tubes corresponding to 400 and $200 \mu \mathrm{g}$ of antibiotic/ml of the broth, but all other control tubes showed very good growth of the test organisms. This indicates that whatever MFC values have been recorded are due to the antibiotics and not to the solvents.

\section{Results and Discussion}

The MFC values obtained for myxin and amphotericin B have been presented in table II. It is clearo that myxin is effective in relatively low concentrationso against all the organisms included in this investiga $-\frac{2}{\Rightarrow}$ tion. The range of concentration required to inhibito growth of the species of Candida, C. immitis, and ${ }^{3}$ $T$. glabrata is quite narrow. The MFCs for strains of a given species, with a few exceptions, show goodcorrelation. The MFCs for 18 of 19 test organismo are $12.5 \mu \mathrm{g} / \mathrm{ml}$ or less, and 14 out of 19 organismsowere inhibited by $6.25 \mu \mathrm{g} / \mathrm{ml}$ or less. Both strains of $B$. dermatitidis were more sensitive to myxino $(0 \cdot 195 \mu \mathrm{g} / \mathrm{ml})$ than to amphotericin B $(0 \cdot 39-78 \mu \mathrm{g} / \mathrm{ml})$ whereas the MFCs for these two antibiotics foro S. schenckii were the same $(6 \cdot 25 \mu \mathrm{g} / \mathrm{ml})$.

This study indicates that low concentrations of myxin inhibit the growth of yeasts and the dimorphic fungi that cause blastomycosis, coccidioidomycosis, and sporotrichosis. In vivo studies are needed to find 0 out whether myxin would be a useful systemic anti-N fungal agent. Such new agents are needed, becauseo amphotericin B and 5-fluorocytocine are sometimeso not effective; for example, in a case of candida endophthalmitis, as described by Skidmore and $\stackrel{9}{+}$ Cockcroft (1974). Also, in this study we have found 0 that myxin yielded very promising results with respecto to a strain of T. glabrata (PLM 305), which was尺 otherwise found to be resistant to 5-fluorocytosine $(2000 \mu \mathrm{g} / \mathrm{ml}$; unpublished data of the Division of $\bar{\sigma}$ Mycology, Provincial Laboratory of Public Health). This strain was isolated from a patient who latero 


\begin{tabular}{|c|c|c|c|c|}
\hline \multirow[t]{2}{*}{ Organism } & & \multicolumn{3}{|c|}{$M F C\left(\mu g / m l^{1}\right)$} \\
\hline & & Myxin & Amphotericin $B$ & 5-Fluorocytosine \\
\hline \multicolumn{2}{|l|}{ Candida albicans 293} & $3 \cdot 125$ & \multirow[t]{6}{*}{$(0 \cdot 39-0 \cdot 78)^{2}$} & \multirow[t]{6}{*}{$(0 \cdot 1-100)$} \\
\hline " $\quad$ guilliermondii & & $6 \cdot 25$ & & \\
\hline ", guilliermondii & 295 & $12 \cdot 5$ & & \\
\hline$"$ krusei" & 296 & $12 \cdot 5$ & & \\
\hline$" \quad k r u s e i$ & 297 & $1 \cdot 56$ & & \\
\hline " & 298 & $0 \cdot 78-1 \cdot 56$ & & \\
\hline " parapsilosis & 299 & $6 \cdot 25-12 \cdot 5$ & \multirow[t]{3}{*}{$(0 \cdot 78-3 \cdot 13)$} & \multirow[t]{4}{*}{$(100)$} \\
\hline$" \quad \quad "$ & 300 & $12 \cdot 5$ & & \\
\hline \# pseudotropicalis & 301 & 0.78 & & \\
\hline & 302 & $1 \cdot 56$ & \multirow{3}{*}{$(0 \cdot 39-6 \cdot 25)$} & \\
\hline tropicalis" & 303 & $12 \cdot 5$ & & \multirow[t]{2}{*}{$(0 \cdot 2-50)$} \\
\hline & 304 & 25.0 & & \\
\hline Torulopsis glabrata & 305 & 1.56 & \multirow[t]{3}{*}{$(0 \cdot 2-0 \cdot 78)$} & \multirow{5}{*}{$\begin{array}{l}2000^{3} \\
(0 \cdot 39-1 \cdot 56)\end{array}$} \\
\hline " $"$ & 306 & $0 \cdot 39-0 \cdot 78$ & & \\
\hline & 307 & 0.78 & & \\
\hline Blastomyces dermatitidis & 218 & $0 \cdot 195$ & \multirow{3}{*}{$\begin{array}{l}0 \cdot 39-0 \cdot 78 \\
0 \cdot 39-0 \cdot 78 \\
(0 \cdot 1-0 \cdot 39) \\
(0 \cdot 78-1 \cdot 56) \\
6 \cdot 25 \\
(3 \cdot 13-100)\end{array}$} & \\
\hline$" \quad \quad \quad$ & 217 & $0 \cdot 195$ & & \\
\hline $\begin{array}{l}\text { Coccidioides immitis } \\
\text { Sporothrix schenckii }\end{array}$ & $\begin{array}{l}288 \\
253\end{array}$ & $\begin{array}{l}0 \cdot 78-1 \cdot 56 \\
6 \cdot 25\end{array}$ & & \\
\hline
\end{tabular}

Table II Sensitivity results of some human pathogenic species of yeasts and systemic fungi to myxin, amphotericin B, and 5-fuorocytosine

${ }^{1}$ The MFC is from duplicate determinations.

'Values in brackets are from the compilation of Shadomy and Espinel-Ingroff (Manual of Clinical Microbiology, 2nd ed., American Society for Microbiology, 1974; pp. 569-574). They are for different strains of the same species.

${ }^{3}$ This value is from a single determination.

died with disseminated torulopsosis. Resistance of some strains of $T$. glabrata and some Candida species to 5-fluorocytosine was noted by Schönebeck and Anséhn (1973).

Pansy (1968) reported successful use of myxin ointment against skin lesions caused by Trichophyton mentagrophytes in guinea pigs. Seven out of 10 artificially induced infections were completely healed. However, no information is available on the absorption or toxicity of myxin from animals or man.

We thank Dr J. W. Carmichael for helpful criticisms of the manuscript. The sample of myxin used in this investigation was kindly supplied by Dr W. E. Scott of Hoffman-La Roche Inc, Nutley, NJ.

The work reported herein was supported by a research grant (MA 5216) from the Medical Research Council of Canada.

\section{References}

Christensen, P. J. (1973). Studies on soil and fresh water Cytophagas. Ph.D. Dissertation, University of Alberta, Edmonton, Alberta.

Haley, L. D. (1972). Laboratory Methods in Medical Mycology. US Department of Health, Education and Welfare, Public Health Service, Center for Disease Control, Atlanta, Georgia.

Pansy, J. G. (1968). Chemotherapeutic activity of myxin in experimental dermatophytosis of guinea pigs. Appl. Microbiol., 16, 817.

Peterson, E. A., Gillespie, D. C., and Cook, F. D. (1966). A wide-spectrum antibiotic produced by a species of Sorangium. Canad. J. Microbiol., 12, 221-230.

Schönebeck, J. and Anséhn, S. (1973). 5-Fluorocytosine resistance in Candida spp. and Torulopsis glabrata. Sabouraudia, 11, 10-20.

Sekhon, A. S., Willans, D. J., and Harvey, J. H. (1974). Deep scopulariopsosis: A case report and sensitivity studies. J. clin. Path., 27, 837-843.

Skidmore, A. and Cockcroft, W. H. (1974). Intravenous feeding and endophthalmitis. Paper M22, The Forty Second Annual Meeting, The Laboratory Division of the Canadian Public Health Association, Ottawa, 27-30 November. 